\title{
Distribution of Surface Components During The Adhesion of Trypomastigotes forms from Trypanosoma cruzi to Phagocytic and Non- Phagocytic Cells
}

\author{
R.C.V. Pinto and T.Souto-Padrón
}

Laboratório de Biologia Celular de Protozoários, Departamento de Microbiologia Geral, Instituto de Microbiologia Prof. Paulo de Góes, CCS, Bloco I, Universidade Federal do Rio de Janeiro, CEP: 21941-590, Rio de Janeiro, RJ, e-mail: souto.padron@micro.ufrj.br

The bloodstream trypomastigotes from Trypanosoma cruzi present a dimorphism, two distinct populations, slender and broad forms. Besides the morphological differences, they also behave distinctly in "in vivo" and "in vitro" conditions. The predominance of one form over the other is dependent on the strain of $T$. cruzi and time of infection. It has been suggested that slender forms are mainly responsible for the infection of the vertebrate cells while broad forms are more able to infect the invertebrate host. Using immunocytochemistry techniques, we have demonstrated that slender and broad trypomastigotes from the same strain do present different distribution of surface antigens (SAPA, LPPG, $80 \mathrm{kDa}$ ) and sugar residue (mannose). So we decided to compare those forms during the adhesion to phagocytic (macrophages) and nonphagocytic cells $\left(\mathrm{LLC}-\mathrm{MK}_{2}\right)$. For these purpose we used a high-resolution-scanning-electronmicroscope (HR-SEM), with detector for backscattered electrons, capable of imaging small details such as the gold particles of $10 \mathrm{~nm}$ used as markers, allied to specific antibodies (SAPA, $80 \mathrm{kDa}$ and LPPG) and lectin (Con-A), to identify components on the surface of the parasite.

Trypomastigote forms were collected from the supernatant of previously infected cells (LLCMK2) and were allowed to interact with non-phagocytic cell for $24 \mathrm{hs}$, and with phagocytic cells for 30 minutes. The samples were washed in PBS and pre-fixed in solution containing formaldehyde $4 \%$, glutaraldehyde grade I $0.1 \%$, sucrose $3.7 \%$ in phosphate buffer $0.1 \mathrm{M}, \mathrm{pH} 7.2$, for one hour. The cells were, then, adhered on a silicon support by way of poly-L-lysine, and incubated with the primary anti-body (serum anti-SAPA, 80kDa, LPPG and Con-A), followed by the secondary anti-body complexed with colloidal gold of $10 \mathrm{~nm}$. Another fixative was used, containing formaldehyde $4 \%$, glutaraldehyde grade II $2.5 \%$, sucrose $3.7 \%$ in cacodylate buffer $0.2 \mathrm{M}, \mathrm{pH}$ 7.2. The samples were post-fixed in a solution of $1 \% \mathrm{OsO}_{4}, 0.8 \%$ potassium ferrocyanide and $5 \mathrm{mM}$ calcium chloride diluted in cacodylate buffer, for one hour. At last, the samples were dehydrated in ethanol, critical-point-dried, carbon coated and observed in a JEOL JSM-6340-F FESEM operating at 5kV.

When observed in HR-SEM, it was found, predominantly, slender trypomastigotes interacting with vertebrate cells. It was also observed that, when comparing the distribution of gold particles, trypomastigotes interacting with non-phagocytic cells presented more gold particles on the surface when incubated with antibodies anti-80kDa and anti-SAPA, an indicative of the presence of $80 \mathrm{kDa}$ and SAPA antigens, than those interacting with phagocytic cells. On the other hand trypomastigotes adhered to phagocytic cells were the only labeled whith Con-A-Au. Those differences might be expected since the mechanism of entry differs for the two cell types. 
Financial support: CNPq, Pronex, Faperj, FUJB/UFRJ and CAPES 


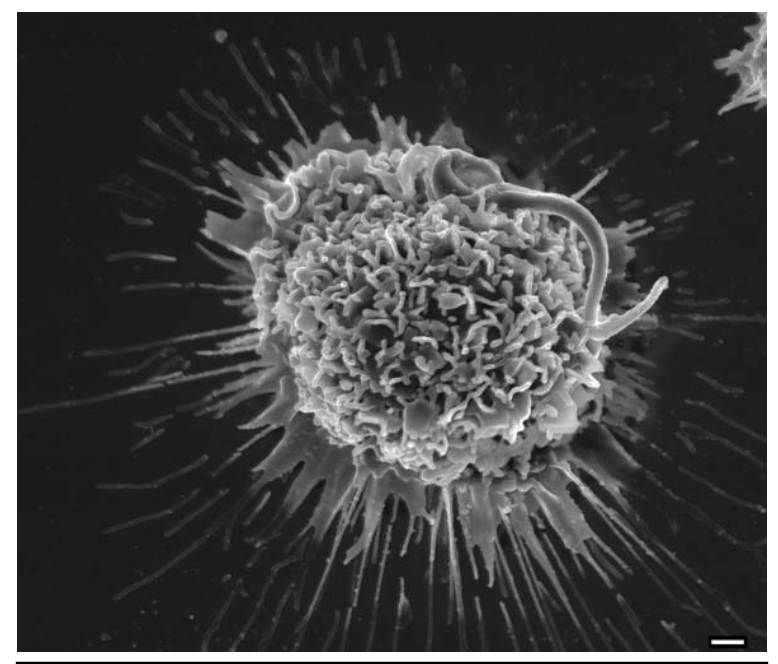

Fig. 1: Slender Tripomastigote adhered to the surface of a Macrophage. Bar: $1 \mu \mathrm{m}$.

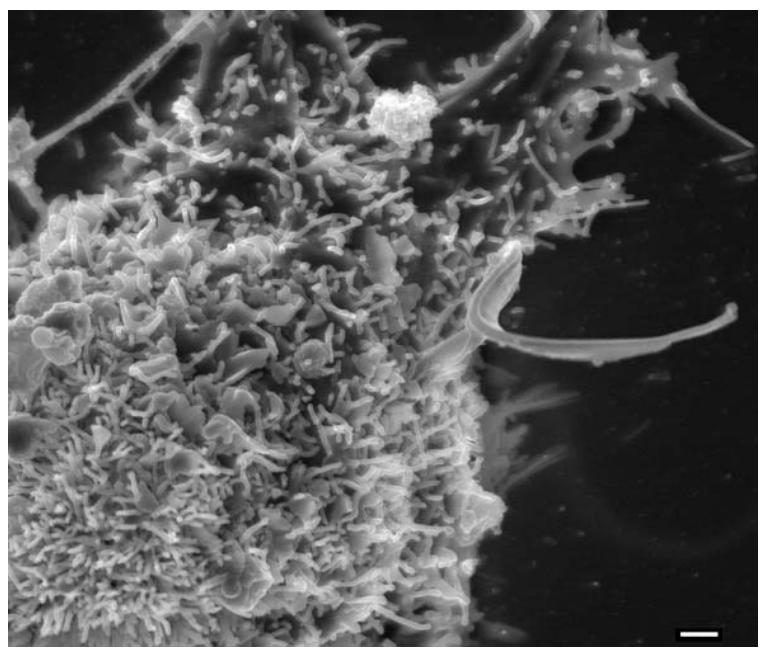

Fig. 2: Slender Tripomastigote adhered to the surface of a LLC-MK 2 cell. Bar:

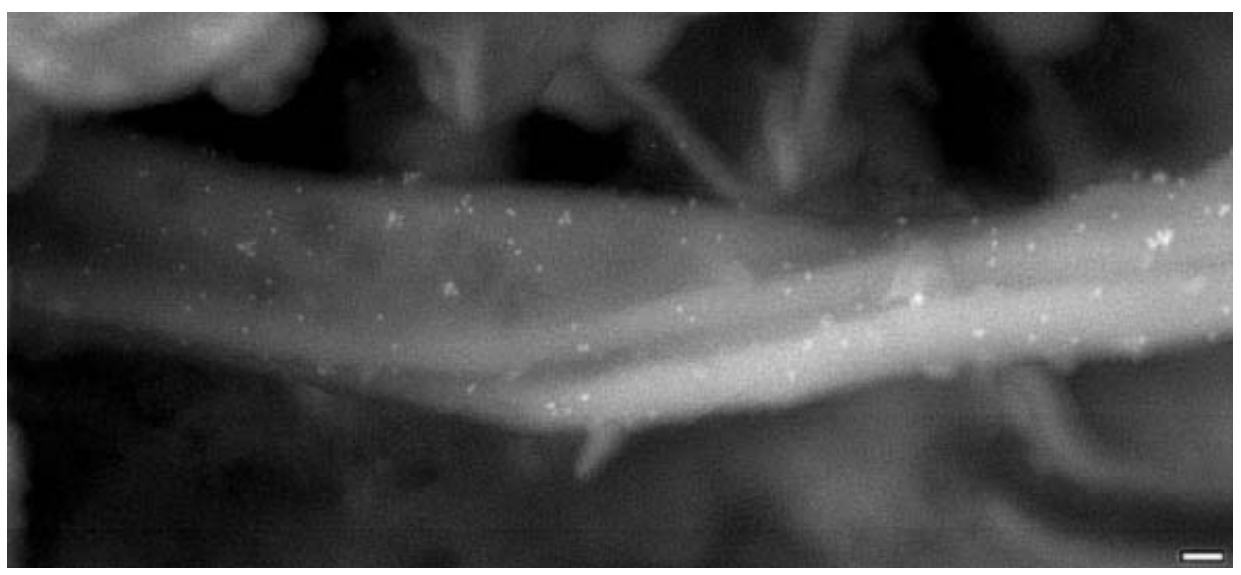

Fig. 3: Slender Tripomastigote adhered to the surface of a macrophage. labeled with anti-SAPA. Bar: $1 \mu \mathrm{m}$.

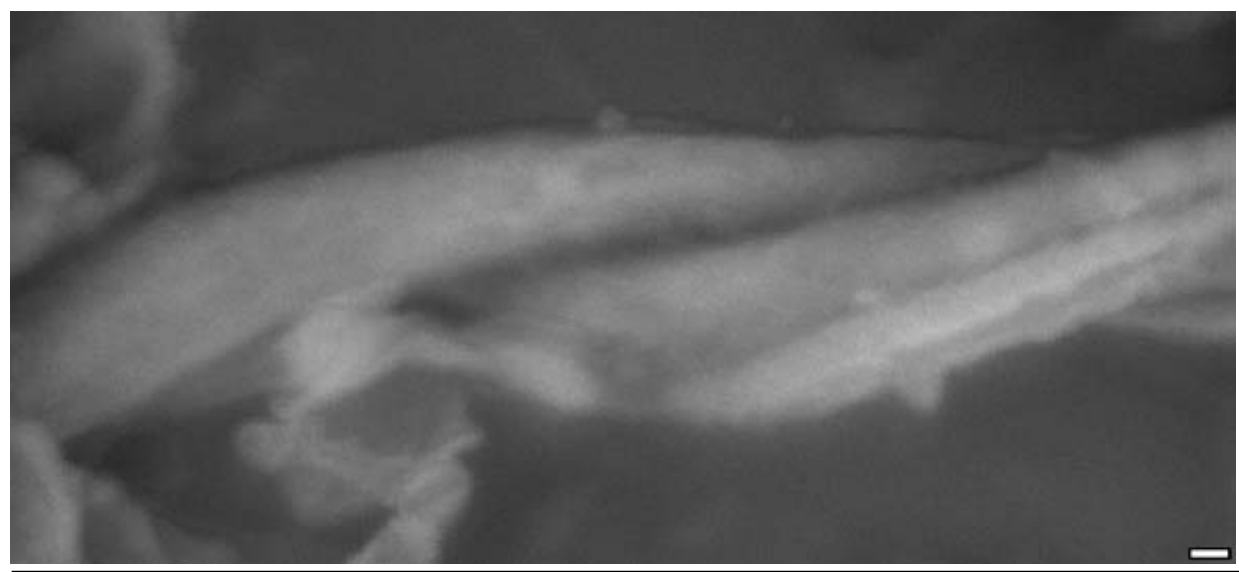

Fig. 4: Slender Tripomastigote adhered to the surface of a LLC-MK 2 labeled with anti-SAPA. Bar: $1 \mu \mathrm{m}$. 